\title{
A Simulation Model for Epidemics of Stem Rust in Ryegrass Seed Crops
}

\author{
W. F. Pfender and D. Upper
}

United States Department of Agriculture-Agricultural Research Service National Forage Seed Production Research Center and Oregon State University Department of Botany and Plant Pathology, 3450 SW Campus Way, Corvallis 97331. Accepted for publication 24 July 2014

\section{ABSTRACT}

Pfender, W. F., and Upper, D. 2015. A simulation model for epidemics of stem rust in ryegrass seed crops. Phytopathology 105:45-56.

A simulation model (STEMRUST_G, named for stem rust of grasses) was created for stem rust (caused by Puccinia graminis subsp. graminicola) in perennial ryegrass grown to maturity as a seed crop. The model has a daily time step and is driven by weather data and an initial input of disease severity from field observation. Key aspects of plant growth are modeled. Disease severity is modeled as rust population growth, where individuals are pathogen colonies (pustules) grouped in cohorts defined by date of initiation and plant part infected. Infections due to either aerial spread or within-plant contact spread are modeled. Pathogen cohorts progress through life stages that are modeled as disease cycle components (colony establishment, latent period, infectious period, and sporulation) affected by daily weather variables, plant growth, and fungicide application. Fungicide effects on disease cycle components are modeled for two commonly used active ingredients, applied preinfection or postinfection. Previously validated submodels for certain disease cycle components formed the framework for integrating additional processes, and the complete model was calibrated with field data from 10 stem rust epidemics. Discrepancies between modeled outcomes and the calibration data $\left(\log _{10}\right.$ [modeled $]-\log _{10}[$ observed $\left.]\right)$ had a mean near zero but considerable variance, with 1 standard deviation $=0.5 \log _{10}$ units (3.2-fold). It appears that a large proportion of the modeling error variance may be due to variability in field observations of disease severity. An action threshold for fungicide application was derived empirically, using a constructed weather input file favorable for disease development. The action threshold is a negative threshold, representing a level of disease (latent plus visible) below which damaging levels of disease are unable to develop before the yield-critical crop stage. The model is in the public domain and available on the Internet.

Additional keywords: azoxystrobin, decision aid, Lolium perenne, propiconazole, wheat.
Plant disease epidemics are complex phenomena in which many biological processes of host and pathogen interact through time and space under the influence of environmental conditions. A mathematical epidemiology model is a simplified representation of the epidemic, capable of quantifying certain of its aspects chosen to meet particular objectives (29). Regression models of epidemics (11) may be used to quantify correlation between some presumably influential factor (e.g., early-season temperature) and an integrated outcome (e.g., disease severity at harvest time), with an objective such as predicting regional disease severity. Complex simulation models that use multiple inputs to quantify disease development may be used to evaluate current understanding of the epidemic processes or to inform management actions such as fungicide applications (2-4). In this article, we describe a simulation model for stem rust caused by Puccinia graminis subsp. graminicola in perennial ryegrass (Lolium perenne) when grown to maturity as a seed crop.

Seed of cool-season grasses such as perennial ryegrass is produced in a limited number of regions in the world. Stem rust is a significant hazard to grass seed crop production in some parts of the world such as New Zealand (10) and the Pacific Northwest of the United States, where a large proportion of the world's perennial ryegrass seed is produced $(21,32)$. In this climate and cropping system, the sexual stage of the fungus is of no epidemiological importance, and the disease cycle consists solely of urediniospore

Corresponding author: W. F. Pfender; E-mail address: pfenderw@onid.orst.edu

http://dx.doi.org/10.1094/PHYTO-03-14-0068-R

This article is in the public domain and not copyrightable. It may be freely reprinted with customary crediting of the source. The American Phytopathological Society, 2015 cycles. In a severe epidemic, a crop unprotected by fungicides can be a total loss (21). Effective fungicides are available but severity and timing of the epidemic can vary markedly from year to year and place to place. In such a situation, a decision aid would be helpful to determine whether fungicides are needed and, if so, the optimum timing for their application (8). Further, a thorough understanding of factors affecting epidemic development can be useful in implementing crop management procedures such as disease scouting schedule.

A range of models has been created for rust disease epidemics. Some rust models are empirical regression models intended for use as posthoc analysis of environmental influences $(6,7)$ or for general predictions about expected disease prevalence and severity $(5,13)$. There are also several examples of simulation models for rust diseases. One of the first was BARSIM, a simulator for barley leaf rust caused by $P$. hordei (31). BARSIM simulated percent leaf area diseased, by means of submodels for well-known disease cycle processes such as infection and latent period as they are affected by environmental conditions. A model for bean rust $(1,4)$ incorporated submodels for infection rate and latent period, as well as changes in host susceptibility with age, to simulate diseased plant area over time. Epidemic progress of leaf rust (P. triticina) in wheat was simulated in a model based on effect of meteorological conditions on the urediniospore infection cycle (26). This leaf rust model also included submodels for leaf growth senescence, and it simulated percentage of rusted leaf area of leaf cohorts (i.e., leaf positions) over time. Another model that combined several wheat diseases, including stripe and leaf rusts, incorporated fungicide effects into a simulation of disease-induced green leaf area loss, and was based on weather-driven plant and pathogen development (3). 
There has not previously been a simulation model published for stem rust of any crop, including perennial ryegrass. In constructing the model described in this article, we relied on the wellresearched biology of wheat stem rust (25) as well as our own previously published research concerning various aspects of ryegrass stem rust biology and management (17-23). The objective in constructing the model was to produce a calculator for a stem rust management decision aid and a heuristic tool for investigating quantitative behavior of ryegrass stem rust epidemics. This article describes construction and parameter estimation for the model based on experiments and data obtained mostly from a single cultivar of perennial ryegrass. An accompanying article (22) presents model performance and validation for this cultivar and a limited number of others.

\section{MATERIALS AND METHODS}

Modeling approach. The model (written in the computer programming language Perl) is a simulator of the stem rust population over time, with a daily time step. The size of the population is expressed as the number of rust colonies (uredinia) occurring on the ryegrass plants occupying $30 \mathrm{~cm}$ of row; because the rows typically are planted $30 \mathrm{~cm}$ apart, this population is also the number of rust pustules in $900 \mathrm{~cm}^{2}\left(1 \mathrm{ft}^{2}\right)$ of field area. The word "colony" is used for convenience to designate each member of the population, even though the colony is initially a germinating spore that then progresses through establishment of an asymptomatic (latent) colony to become an erumpent pustule (visible and sporulating), then a dead (nonsporulating) pustule. The overall approach is to model the rust population as a collection of cohorts, each cohort defined as the colonies originating on a specific day and in relation to a specific anatomical part of the plants. Each cohort's size (number of colonies) is determined at the time it originates, and subsequently can change each day in response to aging, plant development, and fungicide activity, as will be described later in this section of the text. The total size of the rust population or the total size of some subset (e.g., pustules killed by fungicide) on any given day is obtained by summing that category across all cohorts. Cohort size at origination and daily changes are determined by model subroutines that quantify disease cycle processes and interact with plant growth. External drivers are inputs of weather data, fungicide exposure, an initializing value for rust population size, and a plant growth benchmark. The model is not spatially explicit (i.e., there is no attempt to account mechanistically for focus development or its effect on epidemic dynamics). Nomenclature for cohorts is presented in Table 1.

Input data. The model requires a value for the initial size of the rust population, called the "seed cohort", at the beginning of the model period (typically set to $1 \mathrm{March}$ ). This initial value is observed directly by field scouting on that date or estimated by the model from an observation on a later date. For the latter case, there is a solver subroutine that runs the model repeatedly to estimate the size that the seed cohort would have been on 1 March, in order to produce the observed value on its observation date.
The model also requires a plant development biofix observation: the date on which the collar of the flag leaf first appears. In practice, this is obtained by field scouting but the model has a default value if this input is not available.

The daily weather input data are in a file summarizing weather observations from the site of the epidemic. There is one row (line) of data for each day of the season from 1 March to the present, and the data columns are date, daily rainfall total, daily weather favorability for infection, and daily heat units. The daily weather favorability is a value calculated from periodic (e.g., every 15, 30, or $60 \mathrm{~min}$ ) observations of temperature and leaf wetness, according to a previously published algorithm (18). The observations typically are from an automated weather station in the field. The daily heat units, termed "latent period units" (LPU), are calculated as previously described (17) and scaled so that 1.0 LPU is the heat-unit accumulation needed for the pathogen to complete a latent period (time between infection initiation and eruption of the sporulating pustule). The cumulative LPU since 1 March is used as the time-like parameter in terms of which most other events are scheduled although, for some subroutines, calendar time (days) is the time driver. The weather input file is designated the "rain, infection favorability value, LPU" (.ril) file.

The model accepts inputs for fungicide application, specifying date of application and the fungicide (from a list of three commonly used fungicides for rust in grasses) applied at full labeled rate.

Modeled biological processes (subroutines). Daily changes in the rust population (colony cohort size and class composition) and plant growth are modeled as several interacting subroutines driven by the inputs described in the previous paragraphs. The following paragraphs provide a description and some of the basic algorithms of the subroutines, and equations and parameters are listed in Tables 1 to 5 .

Plant growth. The timing and rate of tiller extension has an important effect on stem rust epidemic development because there is a process of within-plant spread of disease (19) that depends directly on dynamics of internode elongation (described in detail in a subsequent section of this article). This process, in which inoculum is dispersed from a sheath lesion onto the plant's culm tissue directly beneath the lesion, is differently affected by fungicides that vary in their ability to interrupt it $(20,23)$. Grass plants grow as an elongating set of telescoping cylinders (internodes), and each internode has a leaf blade as well as a leaf sheath that wraps around a stem segment. The top (last-emerged) segment, typically the longest, of the plant bears the inflorescence. During tiller elongation, each new segment emerges from within the nextolder segment. The plant-part nomenclature used in the model is shown in Figure 1, reproduced from a previous publication (23). As described in that publication, the rate of growth and the size of each internode can be calculated with equations of a sigmoid curve that uses LPU as the independent variable (Table 2) (see also Figure 2 by Pfender and Eynard [23]). The "b" parameter (Table 2) controls the timing of initiation for each segment. The relative values of the $\mathrm{b}$ parameters for the different plant parts control how they overlap in time, and the plant development biofix

TABLE 1. Pathogen cohort classes for model of Puccinia graminis subsp. graminicola on perennial ryegrass ${ }^{\mathrm{a}}$

\begin{tabular}{|c|c|c|c|}
\hline Class & Life stage & Visibility ${ }^{b}$ & Comments \\
\hline le & Latent & Exposed & Aerial-spread infections start as le, become ee after 1.0 LPU \\
\hline lc & Latent & Covered & Contact-spread infections start as lc, may become le, become ec or ee \\
\hline ee & Erumpent & Exposed & The only class that produces inoculum and that is counted as visible disease \\
\hline eei & Erumpent & Exposed & Source pustules for contact-spread infections; subset of ee, located on sheaths and tracked as interior-facing \\
\hline ec & Erumpent & Covered & Pustules on stem section that has not, and may or may not ever, emerge from enclosing sheath \\
\hline de, $\mathrm{dc}$ & Dead & Either & Pustules die of old age (2.5 LPU) or due to fungicide; de and dc produce no inoculum \\
\hline
\end{tabular}

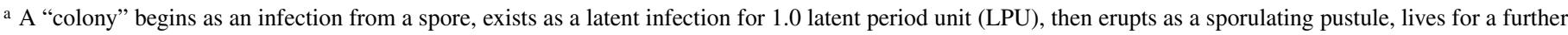
1.5 LPU, then dies.

b A colony may be located on exposed plant tissue or may be located on plant internode tissue covered by an enclosing sheath. 
date (see "Input data" section) places the whole sequence in time. Only the top four internodes (including inflorescence) of the plant are explicitly modeled. A ryegrass plant typically has several additional, older internodes that are smaller and less important in stem rust epidemic development. Plant surface areas for each plant-part class are calculated as the area of a cylinder (Table 2).

Another aspect of plant growth calculated independently in a different subroutine is $\mathrm{A}_{\mathrm{T}}$, the total plant area (in square centimeters) per $30 \mathrm{~cm}$ of row (Table 2). The expression for total plant area was derived empirically by fitting a polynomial equation to data from measurements of destructively sampled plant material per $30 \mathrm{~cm}$ of row, collected periodically during several different growing seasons.

The equation for $\mathrm{A}_{\mathrm{T}}$ (Table 2) describes an increase in plant area to a maximum $\left(12,877 \mathrm{~cm}^{2}\right.$ at LPU $\left.=5.5\right)$, then a decrease as leaves senesce and die (Fig. 2). Total plant area is used in the model for calculating available sites for infection. The decrease in plant area (starting at LPU $=5.5$ ) is used to model the decrease in available infection sites and in number of existing colonies (latent, erumpent, or dead) of this biotrophic pathogen on plant tissue that is removed by senescence. Number of potentially infectable sites is calculated as total plant area divided by the area of an average pustule, taken to be $5 \mathrm{~mm}^{2}$. $\mathrm{A}_{\mathrm{T}}$ includes the area of the top four internodes as well as the remainder of the plant biomass (leaf blades and lower internodes), which is not independently modeled. This remaining area is placed in the plant-part class "other", and its value is obtained by subtracting from $\mathrm{A}_{\mathrm{T}}$ the summed areas of the explicitly modeled internodes.

Infections. Two different types of infection process are modeled: infections due to aerial spread of inoculum and infections spread

TABLE 2. Equations and parameters for plant growth submodels ${ }^{\mathrm{a}}$

\begin{tabular}{|c|c|c|c|}
\hline Process or quantity & Units & Equations & Parameters \\
\hline $\begin{array}{l}\mathrm{L}_{\text {plpart }} \text {, stem or sheath length, by plant part } \\
\text { (e.g., stem0, stem } 1 \text {, sheath } 1)^{\mathrm{b}}\end{array}$ & $\mathrm{cm}$ & $\begin{array}{l}\mathrm{L}=\{a /(1+\exp [(b-x) / c])\}-d \cdot a \\
\text { where } x=\mathrm{LPU} \text { since } 1 \mathrm{March}\end{array}$ & $\begin{array}{l}\text { Parameters } a, b, c, d \text { for each plant part: } \\
\text { st0 } 37.5,5.65,9.72,0.13 \\
\text { st1 } 21.6,4.60,0.60,0.21 \\
\text { st2 } 18.3,3.65,0.60,0.32 \\
\text { st3 } 13.6,2.74,0.54,0.34 \\
\text { st4 } 9.7,2.00,0.55,0.50 \\
\text { sh1 } 17.3,4.23,0.38,0.30 \\
\text { sh2 } 14.3,3.30,0.45,0.40 \\
\text { sh3 } 11.0,2.70,0.55,0.30 \\
\text { sh4 } 8.9,2.00,0.60,0.50\end{array}$ \\
\hline $\begin{array}{l}\mathrm{A}_{\text {plpart}}, \text { surface area of a class of plant part } \\
\text { (e.g., st } 1, \operatorname{sh} 1)^{\mathrm{c}}\end{array}$ & $\mathrm{cm}^{2}$ & $\mathrm{~A}_{\text {plpart }}=\mathrm{t} \cdot \mathrm{L}_{\text {plpart }} \cdot \pi \cdot \mathrm{d} \cdot 0.5$ & $\begin{array}{l}\mathrm{d}=\text { diameter }=0.17 \mathrm{~cm} \text { for } \mathrm{st} 1-4, \operatorname{sh} 1-4 \\
\mathrm{~d}=0.2 \text { for } \mathrm{st} 0\end{array}$ \\
\hline $\mathrm{A}_{\mathrm{T}}$, total plant area & $\mathrm{cm}^{2}$ & $\begin{array}{l}\mathrm{A}_{\mathrm{T}}=976 \text { if } \mathrm{LPU}<0.59 \\
\mathrm{~A}_{\mathrm{T}}=8,858 \text { if } \mathrm{LPU}>8.9 \\
\mathrm{~A}_{\mathrm{T}}=1,786-2,919 x+2,911 x^{2}-505.1 x^{3}+25.27 x^{4}\end{array}$ & $\begin{array}{l}x=\text { LPU since } 1 \text { March, for } 0.59<\text { LPU }<8.9 \\
\ldots \\
\ldots\end{array}$ \\
\hline “Other" area (not st/sh 0-4) & $\mathrm{cm}^{2}$ & $\mathrm{~A}_{\text {other }}=($ total plant area $)-\Sigma\left(\mathrm{A}_{\text {plpart } 0-4}\right)$ & $\ldots$ \\
\hline Number of tillers $(\mathrm{t})^{\mathrm{d}}$ & Integer & $\ldots$ & $t=325$ \\
\hline
\end{tabular}

a Plant areas are per $30 \mathrm{~cm}$ of row (equivalent to $0.09 \mathrm{~m}^{2}$ of field area). LPU = latent period unit.

${ }^{\mathrm{b}}$ Lengths were modeled for five stem internodes (st 0 , st 1 , st2, st3, and st 4 ) and four sheath internodes (sh $1, \operatorname{sh} 2$, sh3, and sh4). Figure 1 provides nomenclature.

${ }^{c}$ Surface areas for cylindrical plant parts are calculated as projected area; therefore, the formula for cylinder area is multiplied by 0.5 .

d Tiller number per $30 \mathrm{~cm}$ of row is assumed, for convenience, to be constant for the model period (1 March to 30 July).

TABLE 3. Equations and parameters for aerial-spread infections ${ }^{\mathrm{a}}$

\begin{tabular}{|c|c|c|c|c|}
\hline Process or quantity & Units & Range & Equations & Parameters \\
\hline $\begin{array}{l}\mathrm{ee}_{\mathrm{c}} \text {, sporulating colonies in a given } \\
\text { cohort }\end{array}$ & Colonies & $\cdots$ & Intermediate simulation output & $\cdots$ \\
\hline $\begin{array}{l}\mathrm{I}_{\text {age }} \text {, proportion of colony's lifetime } \\
\text { spore output for a given age (days } \\
\text { after eruption) }\end{array}$ & Dimensionless & $\begin{array}{c}0-0.2 \\
\operatorname{sum}=1.0\end{array}$ & Lookup Table & $\begin{array}{l}\text { For } 23 \text { days starting at day } 0:(0.001 \\
0.005,0.02,0.06,0.13,0.12,0.11,0.09 \\
0.08,0.07,0.06,0.05,0.04,0.03,0.02 \\
0.02,0.02,0.01,0.01,0.01,0.01,0.01)\end{array}$ \\
\hline $\begin{array}{l}\text { Sum of inoculum released across all } \\
\text { cohorts }\left({ }_{c} \text { is cohort index }\right)\end{array}$ & Colony equivalents & $\ldots$ & $\Sigma\left\{(\mathrm{ee})_{\mathrm{c}} \cdot\left(\mathrm{I}_{\mathrm{age}}\right)_{\mathrm{c}}\right\}$ & $\cdots$ \\
\hline $\begin{array}{l}\text { I = sum of inoculum reaching plant } \\
\text { surfaces }\end{array}$ & Colony equivalents & $\cdots$ & {$\left[\Sigma\left\{(\mathrm{ee})_{\mathrm{c}} \cdot\left(\mathrm{I}_{\mathrm{age}}\right)_{\mathrm{c}}\right\}\right] \cdot 10^{-(\text {Rain/w })}$} & Rain is $\mathrm{mm}$ in previous $24 \mathrm{~h}$; $\mathrm{w}=50$ \\
\hline $\begin{array}{l}\text { InfVal, weather favorability for } \\
\text { infection }\end{array}$ & Dimensionless & $0-3.0$ & $3 \cdot\left[1-\mathrm{e}^{(-0.0031 \times(\text { DHwIndex })}\right]$ & $\begin{array}{l}\text { See ref. } 18 \text { for DHwIndex algorithm, } \\
\text { degree-h of wetness overnight and } \\
\text { morning }\end{array}$ \\
\hline WFct, weather effect on infection & Dimensionless & $0-1,000$ & {$\left[10^{(\mathrm{InfVal})}\right]-1$} & .. \\
\hline $\begin{array}{l}\text { S, susceptibility of plant part to } \\
\text { infection }\end{array}$ & Dimensionless & $0.01-1.0$ & $\begin{array}{l}=1.0 \text { if } \mathrm{LPU}<\mathrm{a}, \\
=0.01 \text { if } \mathrm{LPU}>\mathrm{b}, \\
=1-(\mathrm{c} \cdot(\mathrm{LPU}-\mathrm{a})) \text { if } \mathrm{a}<\mathrm{LPU}<\mathrm{b}\end{array}$ & $\begin{array}{l}\text { Plant part: }(\mathrm{a}, \mathrm{b}, \mathrm{c})=\mathrm{st} 0:(8.5,10.0 \text {, } \\
0.66) ; \text { st } 1 \& \text { sh1: }(7.5,9.0,0.66) \text {; st2\&sh2: } \\
(6.5,8.0,0.66) ; \text { st\&sh3: }(5.0,6.5,0.66) \text {; } \\
\text { st4\&sh4: }(4.0,5.0,0.99) ; \text { 'Other': }(2.7 \text {, } \\
7.0,0.23)\end{array}$ \\
\hline$k$, infection ratio & $\begin{array}{l}\text { New colonies per } \\
\text { sporulating colony } \\
\text { equivalent }\end{array}$ & $0.04-0.2$ & $\begin{array}{l}=0.04 \text { if } \mathrm{LPU}<4.0, \\
=0.20 \text { if } \mathrm{LPU}>5.2, \\
=0.133 \cdot \mathrm{LPU}-0.493 \text { if } 4.0<\mathrm{LPU}<5.2\end{array}$ & $\cdots$ \\
\hline $\begin{array}{l}\mathrm{A}_{\mathrm{A}}=\text { available sites, calculated for } \\
\text { each plant part }\end{array}$ & Infection sites & $0-257,540$ & $=\left(\mathrm{s} \cdot \mathrm{A}_{\mathrm{T}}\right)-$ sum of all colonies & $\mathrm{s}=$ sites per $\mathrm{cm}^{2}=20$ \\
\hline $\begin{array}{l}\mathrm{F}=\text { fungicide effect on colony } \\
\text { survival }\end{array}$ & Dimensionless & $0-1.0$ & See Table 5 & $\cdots$ \\
\hline $\begin{array}{l}\text { New infections (new colony units } \\
\text { produced) }\end{array}$ & Colonies & $0-257,540$ & $\operatorname{Inf}=A_{A} \cdot\left\{1-e{ }^{(-k \cdot F \cdot I \cdot W F c t r)} /\left(A_{T}\right)\right] \cdot S$ & $\cdots$ \\
\hline
\end{tabular}

a All units are per $30 \mathrm{~cm}$ row, and calculated daily. LPU = latent period unit. 
by direct contact. In aerial spread (Table 3), spores originating in pustules are considered to be dispersed randomly across the classes of extant plant area (sheath, stem, and leaves), and there is no relationship specified between location of the inoculum source and the new infection site (i.e., spores arising on all plant parts enter a common pool from which they are distributed uniformly onto the area of all plant parts). There is no modeling of spatial distribution such as aggregation and focus development. This assumption of random dispersal is clearly a simplification of the actual phenomenon but was used to make the model more tractable in our modeling effort. For contact spread (Table 4), new infections occur as a result of contact between particular parts of the extending tiller. Specifically, contact spread occurs from infected leaf sheaths to the internode it encloses as that internode emerges (described in detail below) (19).

Infections from aerial spread. The daily number of new infections of this type is a function of several factors (Table 3): inoculum load, favorability of weather, susceptibility of plant tissue, amount of uninfected plant area available, and optional fungicide factor. The daily number of new infections of this type is calculated separately for each class of plant-part (stem0, stem1, sheath1, and so on) (Table 2).

TABLE 4. Equations and parameters for contact-spread infections ${ }^{\mathrm{a}}$

\begin{tabular}{|c|c|c|c|c|}
\hline Process or quantity & Units & Range & Equations & Parameters \\
\hline $\begin{array}{l}\text { eei }_{c}, \text { source pustules by plant-part class } \\
\text { (sheaths only) for each cohort }(\mathrm{c})^{\mathrm{b}}\end{array}$ & Colony units & $\cdots$ & $\Sigma\{\text { eei }\}_{\text {c,plpart }}$ is an intermediate output of simulation & $\ldots$ \\
\hline Length change $(\Delta \mathrm{L})$, by plant-part class & $\mathrm{cm}$ & $\ldots$ & $\mathrm{L}_{\text {today }}-\mathrm{L}_{\text {yesterday }}$ & See Table 2 \\
\hline $\begin{array}{l}\text { New infections (new colony units } \\
\text { produced), by plant-part class }\end{array}$ & Colonies & $0-\mathrm{t} \cdot($ pust $/ \mathrm{L}) \cdot \Delta \mathrm{L}_{\text {plpart }}$ & $\operatorname{Inf}_{\text {plpart }}=\Sigma\{\text { ee }\}_{\text {c,plpart }} \cdot($ pust $/ \mathrm{L}) \cdot \Delta \mathrm{L}_{\text {plpart }}$ & $\begin{array}{l}\mathrm{t}=325 \text { tillers } \\
\text { pustules } / \mathrm{L}(\mathrm{cm})=15\end{array}$ \\
\hline
\end{tabular}

a All units are per $30 \mathrm{~cm}$ row, and calculated daily.

b Source of spores for contact-spread infections. They are located on sheaths, and they shed spores onto the enclosed internode.

TABLE 5. Surviving proportion (0 to 1.0) of stem rust colonies, as affected by fungicides applied and timing of application ${ }^{\mathrm{a}}$

\begin{tabular}{|c|c|c|c|c|}
\hline \multirow[b]{2}{*}{ Fungicide timing, colony state ${ }^{b}$} & \multirow[b]{2}{*}{ Days $^{\mathrm{c}}$} & \multicolumn{3}{|c|}{ Success rate of colony survival, by fungicide ${ }^{\mathrm{d}}$} \\
\hline & & Propiconazole & Azoxystrobin & Propiconazole + azoxystrobin \\
\hline \multicolumn{5}{|l|}{ Preinoculation } \\
\hline \multirow[t]{23}{*}{ Infection establishment } & 23 & 0.800 & 0.440 & 0.440 \\
\hline & 22 & 0.800 & 0.440 & 0.440 \\
\hline & 21 & 0.800 & 0.440 & 0.440 \\
\hline & 20 & 0.800 & 0.400 & 0.400 \\
\hline & 19 & 0.800 & 0.356 & 0.356 \\
\hline & 18 & 0.800 & 0.311 & 0.311 \\
\hline & 17 & 0.800 & 0.267 & 0.267 \\
\hline & 16 & 0.800 & 0.222 & 0.222 \\
\hline & 15 & 0.672 & 0.182 & 0.182 \\
\hline & 14 & 0.592 & 0.169 & 0.169 \\
\hline & 13 & 0.512 & 0.151 & 0.151 \\
\hline & 12 & 0.440 & 0.133 & 0.133 \\
\hline & 11 & 0.368 & 0.120 & 0.120 \\
\hline & 10 & 0.312 & 0.107 & 0.093 \\
\hline & 9 & 0.256 & 0.093 & 0.071 \\
\hline & 8 & 0.208 & 0.080 & 0.058 \\
\hline & 7 & 0.160 & 0.071 & 0.040 \\
\hline & 6 & 0.128 & 0.062 & 0.027 \\
\hline & 5 & 0.096 & 0.053 & 0.018 \\
\hline & 4 & 0.072 & 0.044 & 0.013 \\
\hline & 3 & 0.048 & 0.036 & 0.013 \\
\hline & 2 & 0.040 & 0.031 & 0.009 \\
\hline & 1 & 0.032 & 0.022 & 0.009 \\
\hline \multicolumn{5}{|l|}{ Postinfection } \\
\hline \multirow[t]{15}{*}{ Latent } & 0 & 0.032 & 0.018 & 0.009 \\
\hline & -1 & 0.032 & 0.018 & 0.009 \\
\hline & -2 & 0.040 & 0.013 & 0.009 \\
\hline & -3 & 0.056 & 0.013 & 0.004 \\
\hline & -4 & 0.080 & 0.009 & 0.004 \\
\hline & -5 & 0.112 & 0.009 & 0.004 \\
\hline & -6 & 0.144 & 0.009 & 0.009 \\
\hline & -7 & 0.184 & 0.013 & 0.013 \\
\hline & -8 & 0.232 & 0.013 & 0.013 \\
\hline & -9 & 0.280 & 0.018 & 0.018 \\
\hline & -10 & 0.336 & 0.022 & 0.022 \\
\hline & -11 & 0.400 & 0.027 & 0.027 \\
\hline & -12 & 0.472 & 0.031 & 0.031 \\
\hline & -13 & 0.520 & 0.040 & 0.040 \\
\hline & -14 & 0.560 & 0.044 & 0.044 \\
\hline
\end{tabular}

a Values in this table are for colonies initiating by the process of aerial spread (Table 3 ).

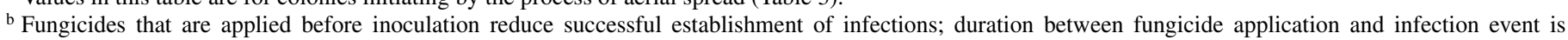
termed "persistence". Fungicides applied after initiation of a rust colony, but before pustule eruption, reduce survival of these latent infections; duration between infection initiation and fungicide application is termed "kickback".

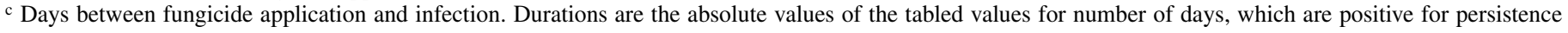
and negative for kickback activity.

${ }^{\mathrm{d}}$ Fungicides are propiconazole, azoxystrobin, or a mixture of the two. See text for dosage details. 
Inoculum for these infections is based on the number of erumpent pustules in the rust population on the previous day. A table in the model program lists the proportion of a pustule's lifetime spore production that is released on each day of its

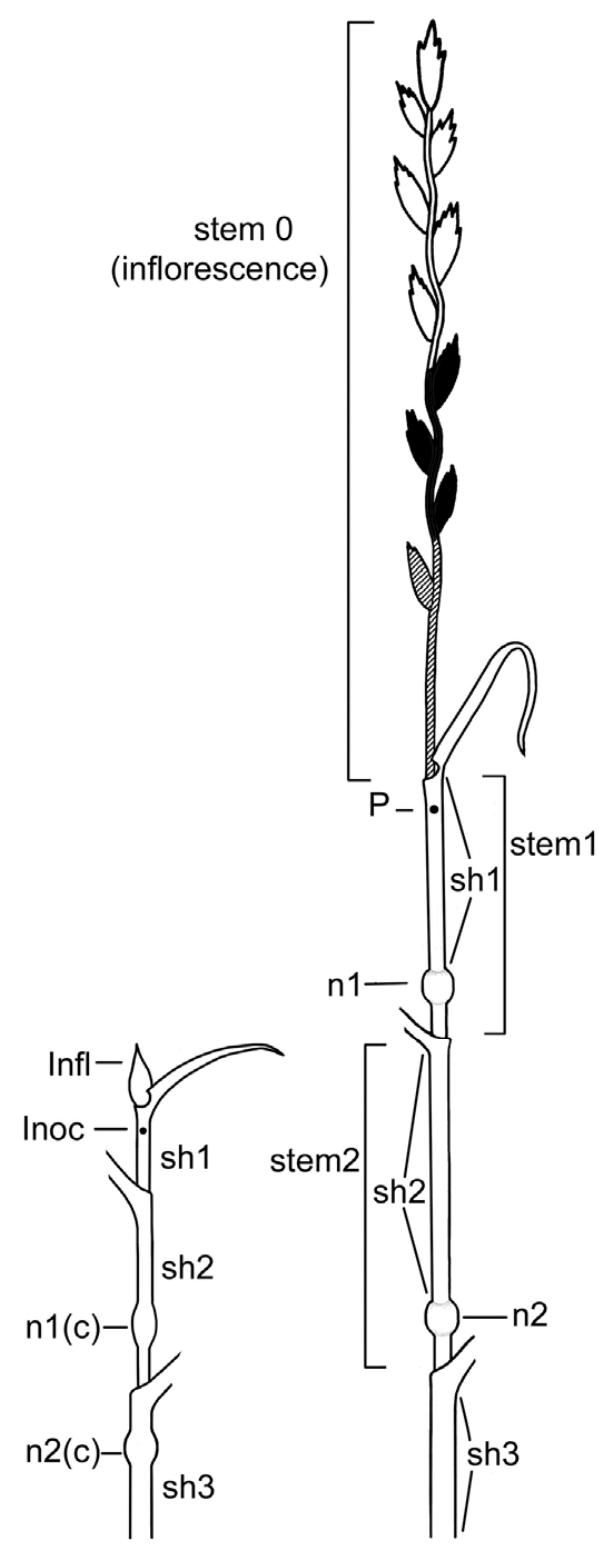

Fig. 1. Morphology of perennial ryegrass and the intraplant spread of stem rust (reproduced from Pfender and Eynard [23]). A developing grass tiller has a telescoped morphology, in which the upper (younger) segments emerge from within the enclosing leaf sheaths of older segments. We label the leaf sheaths from youngest (sh1) to oldest (sh3). Each sheath extends upward from its subtending node (n) (e.g., sh1 extends from n1). The segment between the top of a sheath and the top of the next-lower sheath is designated a stem segment; the inflorescence (Infl) is designated stem0 and successively older stems are stem1 and stem2. In the diagram, Puccinia graminis is applied to an inoculation site (Inoc) on sh1 at Time 1 (left), when $\mathrm{n} 1$ and $\mathrm{n} 2$ are covered (c) by sh2 and sh3, respectively; much of sh1 is still enclosed in sh2; and Infl is just emerging from within sh1. By Time 2 (right), the tiller has extended so that $\mathrm{n} 1$ and $\mathrm{n} 2$ are exposed and stem 0 (Infl) has elongated to its full length. At Time 2, intraplant spread of the pathogen has occurred as new infections have arisen on stem0 due to inoculum released from the sporulating lesion on the inner surface of the pustule $(\mathrm{P})$ on sh1. Infections on Infl that occurred $>1$ latent period before Time 2 have now erupted (indicated by the black fill), and infections that occurred $<1$ latent period before Time 2 have not yet erupted (indicated by hatched fill). The upper portion of Infl moved past the Inoc site during the first latent period after Time 1, when there was not yet any inoculum released from the pustule on sh1, and, therefore, is disease free (indicated by no fill). 23-day life. The proportions are based on a curve fitted to data obtained by collecting spores from pustules at 2- to 3-day intervals (9). Thus, each cohort of pustules produces a specified proportion of its lifetime total inoculum on any given day, according to its age on that day, multiplied by the population size of that cohort. Total inoculum produced on a given day is the sum of all cohorts' sporulation on that day. After this calculation the effective inoculum is then reduced if there was rainfall in the previous $24 \mathrm{~h}$, assumed to wash some of the spores from pustules and onto the ground, thereby preventing their aerial dispersal (W. Pfender and D. H. Gent, unpublished data). Others have noted a detrimental effect to $P$. graminis spore germination due to excessive water on leaves (27), which also might be correlated with amount of rainfall. For the reduction due to rain, inoculum is multiplied by $10^{-(\mathrm{mm} \operatorname{rain} / w)}$, where $w$ is a scaling parameter.

The daily weather favorability factor, provided in the .ril input file, is calculated from the daily temperature and moisture data as described in the "Inputs" section of this article. Weather favorability factor value (range 0 to 3.0) is used as an exponent of 10 to produce WFctr (range 0 to 1,000 ), the relative favorability for infection success by the inoculum present (18).

A decrease in susceptibility to rust infection with leaf age has been reported for other rust diseases $(3,4,24)$. We previously conducted experiments in which perennial ryegrass plants of several different developmental stages were inoculated simultaneously under identical conditions, and we found that older tissue was less susceptible than younger tissue within each developmental stage (19). Thus, the highest disease severities occurred on expanding or newly expanded leaves or stem segments (19). Also supporting the idea that susceptibility decreases with tissue age is the observation that, during an epidemic of Lolium stem rust in the field, mature leaf and stem tissues remain uninfected despite infection-favorable weather and large amounts of ambient inoculum (W. F. Pfender, personal observation). The model incorporates the inverse correlation of susceptibility with tissue age by applying a susceptibility factor to each class of plant part (stem0, sheath1, stem1, and so on). Susceptibility factor is 1.0 (fully susceptible) until the plant part reaches full extension (defined as $1 \mathrm{~cm}$ shorter than its asymptotic maximum length), then decreases at a linear rate over the next 1.5 LPU to reach 0.01 , at which value it remains. For the "other" category of plant parts (which is principally the leaf blades), the same calculation is applied to each cohort of leaves (leaf5, leaf4, and so on) and combined into one curve by averaging susceptibility by area across all leaf cohorts for each day of the season.

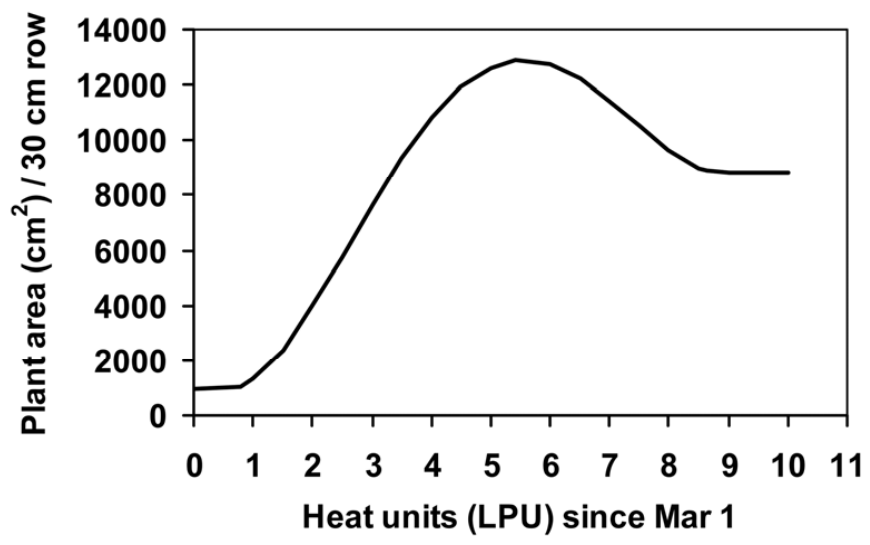

Fig. 2. Total green plant area of a perennial ryegrass seed crop as a function of physiological time (heat units). The polynomial equation was fit to data obtained by measuring surface area of harvested plant material sampled at various times during several growing seasons. Table 2 provides parameter values. 
The infection ratio $k$ (Table 3 ) is a proportionality factor that must be empirically calibrated from field observations, as described later in this article. The function of $k$ is to incorporate several known and unknown processes that link inoculum quantity (sporulating pustule equivalents) to number of new infections produced under optimally favorable weather conditions (and absence of fungicide). The probability of successful spore dispersal (i.e., probability that spores leaving a source pustule will arrive at a potential infection site) is implicit as one component affecting this proportion but is not explicitly modeled. This dispersal probability is affected by many spatial aspects (e.g., aggregated distribution of source pustules in the field and effect of canopy position on dispersal) and other processes that are not specified in this model.

There is a fungicide factor $F$ (see "Fungicide effects", below), ranging from 0 to 1.0 , that can (among other effects) reduce the viability of the inoculum that arrives at the plant surface.

The inoculum, weather favorability, infection ratio, and fungicide factor are used to compute the inoculum's probability of infection per unit plant area in the canopy. A spore that arrives at a plant surface where conditions are favorable for infection may, however, be unable to cause an infection (i.e., unable to add to the rust population) because that site is already infected. The available_sites factor in the equation accounts for this process by subtracting infected sites from plant area. Calculation of number of available sites is done separately for each plant-part class, and this calculation results in infections being distributed among plant-part classes proportional to their relative contribution to total plant area available for infection.

Infections from contact spread. During the tiller extension phase of plant growth, stem rust disease can spread from an active pustule on a leaf sheath to the enclosed plant parts (younger sheaths and stems) as they elongate within the cylinder formed by the infected sheath (19). By this process (Table 4), a single active pustule on the sheath (a "source pustule") can produce 10's or 100 's of additional infections on the extending young tissues enclosed within the sheath. Thus, contact spread is very important quantitatively in stem rust epidemic development. A quantitative model for the number of new infections produced per day per source pustule by this process has been published previously (23). Briefly, the equations for plant internode growth are used to calculate length of the enclosed plant part receiving inoculum from the interior-facing surface of a source pustule each day during elongation. The number of source pustules on a given class of sheaths (e.g., sheath3, sheath2, sheath1) on a given day is derived from the assignment of "aerial-spread infections" (see previous section) to that sheath class one latent period earlier. Thus, the number of new daily infections from contact spread is proportional to the number of source pustules and elongation rate of enclosed internodes. Each class of sheath plus enclosedinternode pairs is modeled separately. Correction is made for source pustules that overlie enclosed internode tissue that has already been infected by a source pustule located lower on the sheath. Some of the infections from contact spread will never be exposed to visible observation because they occur on that part of the internode that remains enclosed in the sheath even at maturity; the model accounts for this outcome through application of the equations for stem and sheath elongation.

Population structure of pustules. The rust population is modeled as a collection of cohorts (Table 2). Based on the known biology of this pathogen, in which infection occurs on a daily cycle near dawn (18), new cohorts are initiated once per day. Each cohort is defined as the new infections (specified as aerial- or contact-spread type) started on a given day on a given plant part. At initiation, the colonies in a cohort are classed as "latent". At 1.0 LPU after initiation of a cohort, the colonies in that cohort change from "latent" to "erumpent". The pustules in a cohort change from erumpent to "dead" at 2.5 LPU after initiation (1.5 LPU after eruption). For pustules derived from contact spread, the additional classes "covered" or "exposed" describe whether or not the section of the internode on which they reside has emerged from the enclosing sheath. A pustule must be erumpent, or erumpent-exposed in the case of cohorts derived from contact spread, to contribute to the inoculum factor in the equation for aerial spread and to be classed as observable disease.

Fungicide effects. The two fungicide classes that are used most commonly to manage ryegrass stem rust are triazoles and strobilurins. In a previous publication, we presented equations for the pre- and postinfection activity of these fungicides, as well as their differing effects on the contact-spread process, based on our data from field and greenhouse experiments (20). Description of the fungicide submodel and its validation in field experiments has been presented (23). The following commercial products (Syngenta, Inc., Basel, Switzerland) and their active ingredients (a.i.) used in these experiments were Tilt (propiconazole at $189 \mathrm{~g}$. a.i./ha), Quadris (azoxystrobin at 165 g. a.i./ha), or Quilt (propiconazole at $185 \mathrm{~g}$ a.i./ha and azoxystrobin at $111 \mathrm{~g}$ a.i./ha).

In the rust simulation model, application of a fungicide produces the following actions (Tables 5 and 6).

(i) In cases when the fungicide has been applied before the infection event, it reduces the effectiveness of inoculum in the "Infection" stage of the aerial-spread infection process. Fungicide activity decreases as time between application and infection initiation increases. This effect (often termed the "persistence" of the fungicide) is implemented in the pathogen survival factor $(F$, range 0 to 1.0) (i.e., the value of $F$ gets larger [more pathogen population units survive] as fungicide activity decreases with time). $F$ is multiplied by the inoculum term in the infection equation (see also Table 3). If fungicide applications are made at intervals less than 21 days, the effects due to each fungicide application are multiplied together for the overlapping days.

(ii) In cases when the fungicide is applied after infections are latent, the fungicide activity (commonly termed "kickback") is implemented by reassigning a proportion of the pustules in any

TABLE 6. Survival or activity rate (0 to 1.0) of stem rust colonies, as affected by fungicides applied to erumpent pustules ${ }^{\mathrm{a}}$

\begin{tabular}{|c|c|c|c|c|}
\hline \multirow[b]{2}{*}{ Colony state ${ }^{\mathrm{b}}$} & \multirow[b]{2}{*}{ Affected process } & \multicolumn{3}{|c|}{ Success rate of affected process, by fungicide ${ }^{c}$} \\
\hline & & Propiconazole & Azoxystrobin & Propiconazole + azoxystrobin \\
\hline ee & Survival & 0.56 & 0.044 & 0.044 \\
\hline ec & Survival & 1.00 & 0.350 & 0.220 \\
\hline ee & Sporulation & 0.26 & 0.018 & 0.013 \\
\hline eei & Contact-spread source & 0.70 & 0.030 & 0.020 \\
\hline
\end{tabular}

a Values in this table are for colonies initiating by aerial or contact spread (Table 3).

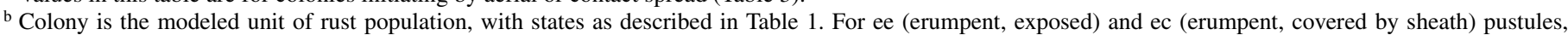
tabled value is the proportion of erumpent pustules (any age) surviving after fungicide application. For surviving ee pustules, tabled value is the relative capacity to act as ee inoculum source (spores released as aerial-spread inoculum) or eei inoculum source (spores released from inner sheath to produce contact-spread infections).

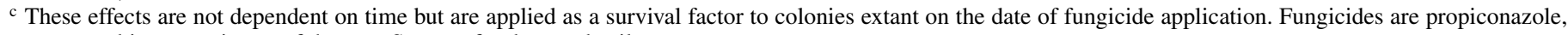
azoxystrobin, or a mixture of the two. See text for dosage details. 
affected cohort from the latent (Table 5) class to the dead class. Latent pustules are most sensitive to fungicide (larger proportion reassigned from latent to dead) immediately after they originate, and become progressively less sensitive (smaller proportion reassigned to dead class) as they approach and pass the end of the latent period (20).

(iii) For pustules already erumpent when the fungicide is applied (Table 6), the fungicide effect reduces their survival and their sporulation $(20,30)$, thereby decreasing the amount of inoculum. This effect is implemented as a factor in the algorithm that translates pustule number and ages into inoculum.

(iv) As a special case of (iii), the capability of a source pustule to produce contact-spread infections can be reduced due to inhibited sporulation from the pustule face located on the inner surface of the sheath. Previous experiments demonstrated that the effect is starkly different for different fungicides (20). The magnitude of the contact-spread outcome of fungicide application depends also on the rate of internode growth at the time of application, modeled via the plant growth algorithms.

Model operation. The model is built to run in UNIX, and there is a version that can be run in Windows DOS mode. The DOS version is available at http://pnwpest.org/cgi-bin/stemrust1.pl, with all documentation, ancillary files, and example files provided. The model is initiated with an observed level of disease, supplied as an external input specifying date and disease level (in pustules per $30 \mathrm{~cm}$ of row). The weather (.ril) input file is needed, as well as the plant growth biofix value and the timing of any fungicide applications. The model will then simulate the rust population and its component categories (such as latent, erumpent, and dead) for each day up to the last day for which weather data are specified in the ril file. The model has instructions to output data in a format that can be used for creating graphs of daily rust population levels across time (Fig. 3). The output can also include an action threshold to indicate when fungicide should be applied. The action threshold is set so as to keep the level of visible disease (i.e., erumpent pustules) below the damage threshold of the disease, $\approx 2,000$ pustules per $30 \mathrm{~cm}$ of row (21), with the use of one or more fungicide applications per season. The threshold is compared with latent + visible disease (not simply the visible disease) to specify when a fungicide spray is required. Depending on the weather conditions and the relative importance of aerial versus contact spread at any particular time, the total (latent + visible) disease typically reaches a given level 1 to 3 weeks before visible disease reaches that level. Another output is the area under the disease progress curve for any desired part of the season. Typically, the 3-week interval centered on the midpoint between anthesis and harvest is selected, because this period has the best correlation between healthy area duration and yield (21).

Model parameterization. Model parameters were set and adjusted in an iterative, multistep process that calibrated the model to match observations from field experiments. The observation data were from a subset of field experiments described in previous research to determine a damage function for stem rust in perennial ryegrass seed crops (21). A brief summary of those experiments follows. From 1998 through 2005, experiments conducted at Oregon State University's Hyslop research farm compared various fungicide treatments (including nontreated) on first- and second-year plantings of perennial ryegrass 'Morningstar' grown to seed-crop maturity in completely randomizedblock designs with three to five replications. Individual plots were 4.2 by $7.5 \mathrm{~m}$ or 4.2 by $16 \mathrm{~m}$ in size. All epidemics were from naturally occurring infections, and epidemic severity differed greatly among years. Between mid-March and mid-July, at intervals of 1 to 3 weeks, disease severity in each plot was determined by visual observation of 5 to 10 sample quadrats. Access to the plots was by a movable platform above the plants, to minimize disturbance of epidemic progress that would result from an observer entering the plots. Full details about disease sampling are in the previous publication (21).

One important challenge in aligning model results with field data was the conversion of sample observations to actual rust population. Early in the season, before the canopy closes over the rows, all the foliage in a sample can be assessed and no conversion is needed. However, as the amount of foliage becomes too large to be feasibly examined in its entirety, our sampling method is to randomly place a square quadrat on the canopy and count what is visible. The ratio of countable disease to total disease through the depth of the canopy depends on depth of the canopy as well as vertical distribution of active (not senescent) plant tissue and disease, which changes during the season. Our approach for developing the conversion algorithm was to periodically take destructive samples through the full canopy depth at the

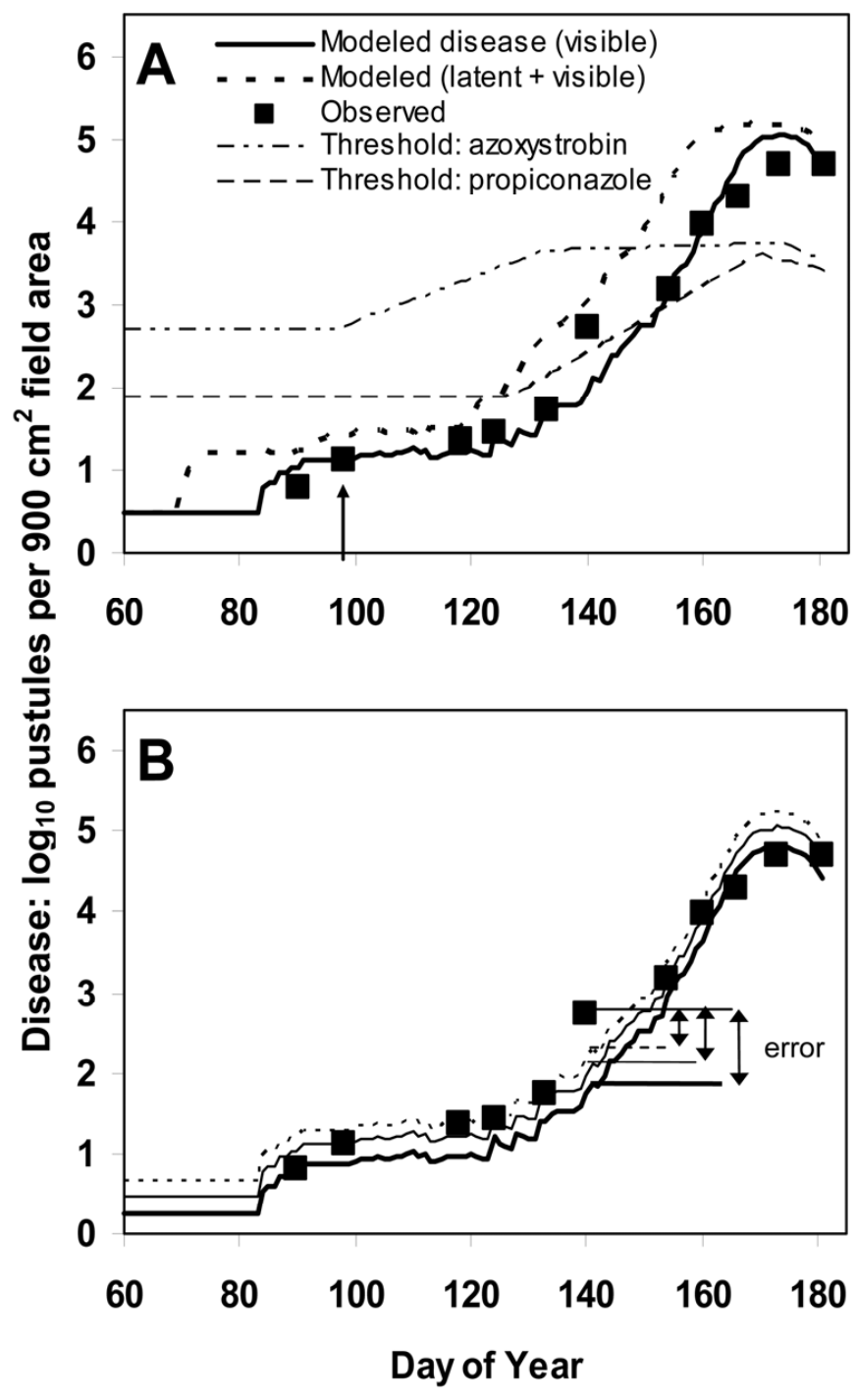

Fig. 3. Graphed output of STEMRUST_G. A, Example of model output displaying the simulated daily levels of visible disease (erumpent pustules, solid heavy line) and total disease (visible + latent infections, dashed heavy line) from an input value of visible disease (date and population) and a file of daily weather data. In this run of the model, disease input value was for 8 April (day 98, arrow). Action thresholds are shown for the two fungicide classes used in disease management. The pictured data were from a nonfungicide check treatment. B, In testing and parameterizing the model, error was calculated as $\left(\log _{10}\right.$ [modeled $]-\log _{10}[$ observed $\left.]\right)$. The model was run several times for each epidemic, initiated with the observed data for successive dates. In this example, the runs for the first three initiation dates are displayed, and the error is indicated for each run's output with respect to the observed value for day 140 . 
locations of randomly selected quadrat samples, and obtain an accurate count of the total disease by scoring the cut samples in the laboratory. We used these data to construct a graph for the ratio of sample data to total-population estimates for $30 \mathrm{~cm}$ of row, as a function of date (Fig. 4). All field observations were converted in this manner before being used in model development and validation.

The data sets were plotted to produce the disease progress curves of visible disease for model parameterization and testing. In total, across years and treatments, there were 36 different epidemic data sets, each consisting of observations from replicated plots. Ten of these data sets, including representatives from 5 of the 8 years, were used in model calibration (this article): three experiments in 1998; two experiments each in 2000, 2001 and 2004; and one experiment in 2005. The other 26 data sets, plus data sets from several other locations in western Oregon, were later used in model validation (22). Each year at the field sites, weather data (air temperature at canopy height, leaf wetness, rainfall, and relative humidity) were collected at $15-$ or 30-min intervals by means of an automated weather station (Campbell Scientific Inc., Logan, UT), as described previously (18).

In addition to the disease progress data sets, other data were collected for use in calibrating the model. At irregular sampling intervals, 25 to 50 tillers were destructively sampled from some of these plots, as well as from plots set up in growers' fields at other locations, and data were obtained on distribution of rust pustules on the various plant parts, as well as average disease severity of the sample. The numbers of pustules on each of the top four stem and sheath segments, and on leaves and lower internodes, were recorded so that ratios could be computed for typical disease distribution among these plant parts at various time points in the epidemic. Data to be used in setting the parameter for duration of pustule life (time between eruption and the cessation of sporulation) were obtained by observation of individual pustules in field plantings between April and June. These individual pustules ( 20 pustules from observations in 2 years) were identified when they had just opened, and their locations were mapped with diagrams for designated leaves on flagged plants. Each pustule was observed at approximately weekly intervals and its condition was recorded. From these data, the average duration between pustule eruption and onset of pustule necrosis was calculated as 1.56 LPU, with a standard deviation of 0.4 LPU.

Comparisons between observed values and model outputs were conducted with archived, full-season data from the 10 experiments. Disease level was plotted as $\log _{10}$ of pustules (Fig. 3A) because the range of severity during the season is typically five or

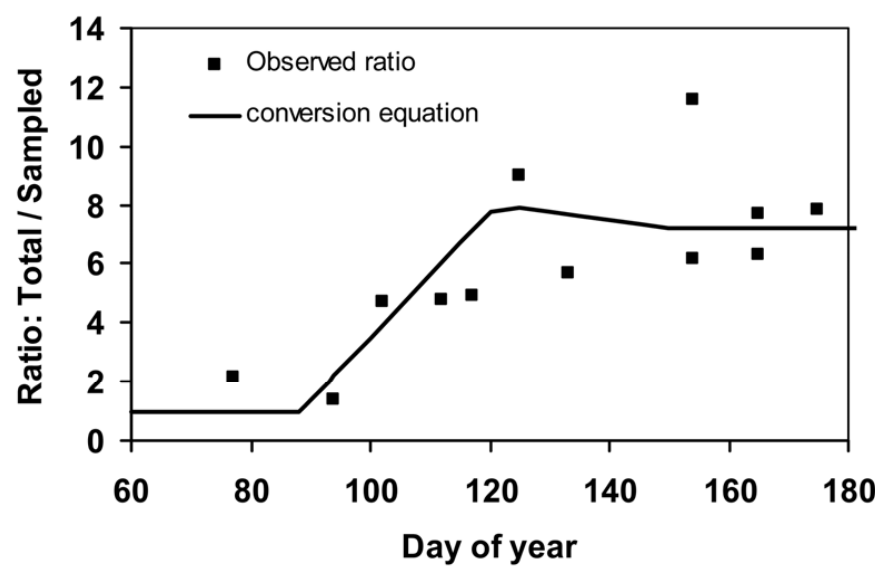

Fig. 4. Ratio of observed disease to total disease (number of pustules) for quadrat-sample counts taken in field plantings of perennial ryegrass. This ratio was used to convert sample observations to total rust population before constructing disease progress curves. See text for details. six orders of magnitude and, thus, a linear plot obscures essential information about disease level during the parts of the epidemic that are most critical for practical disease management (10 to 2,000 pustules per $30 \mathrm{~cm}$ ). Several runs of the model were conducted with each epidemic data set, using the full-season weather data and field observations. For each epidemic, one run was initiated at each observation date, with its observed disease level as the input value (Fig. 3B). For example, an epidemic with 11 observation dates would have 10 runs: the run initialized on observation date 1 would produce output to include disease severities for dates 2 through 11 , the run initialized on date 2 would produce output for dates 3 through 11, and so on. Thus, the output for each model run of an epidemic included daily disease severity values that could be compared with all observation dates subsequent to the run initialization date. Error (i.e., discrepancy, for each comparison) was quantified as $\log _{10}$ (modeled) $\log _{10}$ (observed). Each discrepancy could be associated with the amount of time elapsed between the model initialization date and target (comparison) date. If the model was a perfect reflection of reality, and if there was no sampling error in the observations, the discrepancy between modeled and observed would be zero at all points.

In the parameter-estimation phase of modeling (this article), parameters were adjusted with the goal of approximating a mean overall difference of zero between modeled and observed values across all training data sets. In calibrating the model, we took as a starting point several of the submodels that we had developed and parameterized previously. Thus, we began with the previously reported algorithms and parameters in the submodels for plant internode extension (23) and we assumed the validity of the infection favorability calculation for weather conditions (18), the heat-units calculation for latent period duration (17), and pustule longevity observations (as described in this article). With these components in place, the first parameter adjusted was the infection ratio $(k)$ using data from nonfungicide treatments. In calibrating the value of $k$, we referred to analysis by Yang and TeBeest (33) documenting an increase in apparent daily infection rate over the course of some epidemics, correlated with a decrease in spatial aggregation of disease. The susceptibility factor algorithm (reduction in susceptibility of the plant part classes with age) was then adjusted (rate of change and final level of susceptibility), with the goal of matching modeled and observed values for overall disease level as well as for observed ratio among disease levels on different plant parts (e.g., inflorescence, sheath sections, and leaves). Data from fungicide-treated plots were examined next and minor adjustments made as needed in the original fungicide submodel parameters $(20,23)$.

In order to gauge the contribution of error variance in the field observations to the evident model error, the $95 \%$ confidence interval (CI) was calculated for each data point of observed disease in the 10 epidemics. The CI was calculated from the three to five replicate-plot values for each mean disease estimate, each replicate-plot value being the average of 5 to 10 sample scores. All observed values were log-transformed before calculation of variance.

The finalized model was used to construct an action threshold for fungicide application. In setting the threshold, we used a rationale similar to the "negative threshold" concept described by Paveley (16). If disease severity remains below the threshold, by use of fungicides when needed, an epidemic cannot develop to economically damaging proportions during the remainder of the crop season. The threshold was derived empirically under the assumptions that (i) the model is accurate and (ii) the disease management goal is to apply fungicides as necessary to keep disease severity $<2 \%$ during the yield-critical period between anthesis and harvest (21). The threshold was constructed by running the model with a composite of actual weather data formulated to represent a reasonable "worst-case" year, while 
varying the input disease level in each of many test model runs. By this process, we determined levels of total infection (latent + erumpent disease) throughout the season at which fungicide application would prevent eventual occurrence of damaging disease levels. For this determination, we allowed repeat applications at intervals of no less than 14 days, consistent with label regulations and common practice.. The composite worst-case weather input (.ril) file for the process was constructed by assembling weather input files (.ril files) from 14 years, and extracting the 75th percentile value of infection favorability for each day of the year. The daily rainfall and LPU columns of the composite .ril were populated using each day's 14-year average for precipitation and daily temperature.

\section{RESULTS}

STEMRUST_G, the simulation model for stem rust of perennial ryegrass, is in the public domain. The Perl code, as well as accompanying files of documentation and example datasets to run the model, are available for download from the grass stem rust estimator website (http://pnwpest.org/cgi-bin/stemrust1.pl).

The parameter values developed to align the model output values with the observed values from field plots are listed in Tables 2 through 6 . In setting the value of the infection ratio $(k)$, a value of $k=0.04$ gave the best fit on average to the observations for early-season epidemic development. However, running the model for season-long data at this value of $k$ gave a poor fit for the mid- to late-season data. We found that a larger value of $k$ was needed later in the season to fit the observations of total disease as well as to approximate the ratio of stemborne to leafborne disease observed in field samples. The algorithm chosen was $k=0.04$ for LPU $<4.0, k=0.2$ for LPU $>5.2$, and a linear increase in $k$ between LPU 4.0 and 5.2 (Table 3), where LPU is cumulative from 1 March. The exponent for reducing inoculum due to rainfall (millimeters per preceding $24 \mathrm{~h}$ ) was set by comparing model outputs for high-rainfall and low-rainfall weather patterns, and determining that the value $10^{-(\mathrm{mm} / 50)}$ gave the best fit across both types of weather pattern. Thus, for example, $15 \mathrm{~mm}$ of rain in a 24 -h period reduces inoculum to $50 \%$ of its non-rain value. The susceptibility factor algorithm (Table 3 ) was set to gradually decrease the level of susceptibility for mature plant parts, and parameterized to remedy a model artifact, not seen in field observations, of a late-season rise in number of infections on all

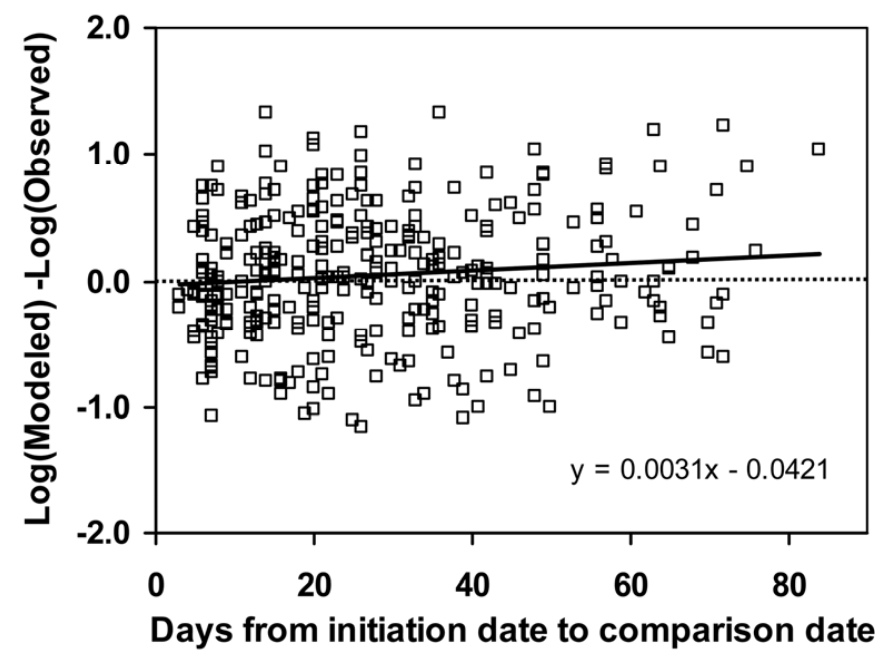

Fig. 5. Distribution of model errors (Fig. 3B) from 10 independent experiments that were used to calibrate parameters of STEMRUST_G, plotted against the number of days between the model initialization date and the target date for comparing corresponding modeled and observed values. Solid line shows linear regression results and dashed line indicates zero error. plant component classes. To approximate the effects of fungicides as observed in the data sets, some revisions were needed in the constants of the previously published fungicide algorithms (23), although the general form of the algorithms was maintained. For example, the survival rate of pustules that are erumpent at the time of fungicide application was revised from 7 to $4.4 \%$ for azoxystrobin and from 70 to $56 \%$ for propiconazole (Table 6 ).

After finalizing the parameters in the model (Tables 2 to 6), the differences between modeled and observed disease levels (Fig. 3B) were calculated, as described in the Methods section, for all 10 experiments. This procedure yielded 317 point comparisons ( $\log _{10}\left[\right.$ modeled] $-\log _{10}$ [observed]). The mean difference across these 317 comparisons was 0.04 (standard deviation $=0.51$ ) (i.e., the model, on average, estimates the disease levels well, having only a slight average bias toward overestimating observed disease). We note that the range of values modeled during a season is approximately six orders of magnitude (from $\log _{10}[1]$ to $\left.\log _{10}[100,000]\right)$. The mean difference of 0.04 , which is in $\log _{10}$ units, can also be expressed as a $+10 \%$ bias $\left(\log _{10}[0.04]=1.1\right)$ in nontransformed values. A scatter plot of these differences as a function of the time duration between the model initialization date and the target date (Fig. 5) indicates that the model error is fairly consistent across durations, having a minor average tendency toward overprediction with increasing time between initialization and target dates. To assess the extent to which the variance in modeling error (modeled values minus observed values) could be a reflection of the intrinsic variance in the observed data points, we examined the $95 \%$ CI for each of the observed-value data points used in the model-training data sets. There were 78 individual data points, for each of which a $95 \%$ CI was computed. These CIs ranged from \pm 0.02 to \pm 1.41 ( $\log _{10}$ values). The 67 th percentile of their frequency distribution was $0.41\left(10^{0.41}=2.6\right.$ fold range) (i.e., for $33 \%$ of these CIs, the upper limit was $\geq 2.6$ times the lower limit). The 95th percentile was 0.76 (5.7-fold range) (Fig. 6). For the model errors themselves ( $\log _{10}[$ modeled] $\log _{10}[$ observed]), the 67 th and 95 th percentile were 0.51 and 1.01 (3.2- and 10.2-fold), respectively (Fig. 6).

The simulated epidemic produced with the composite weather input file and used for constructing the action thresholds was slightly more severe than the simulated epidemic produced with the single most favorable epidemic year among the 14 years of available weather data. Specifically, when both simulated epidemics were initiated with the same disease value, the composite-

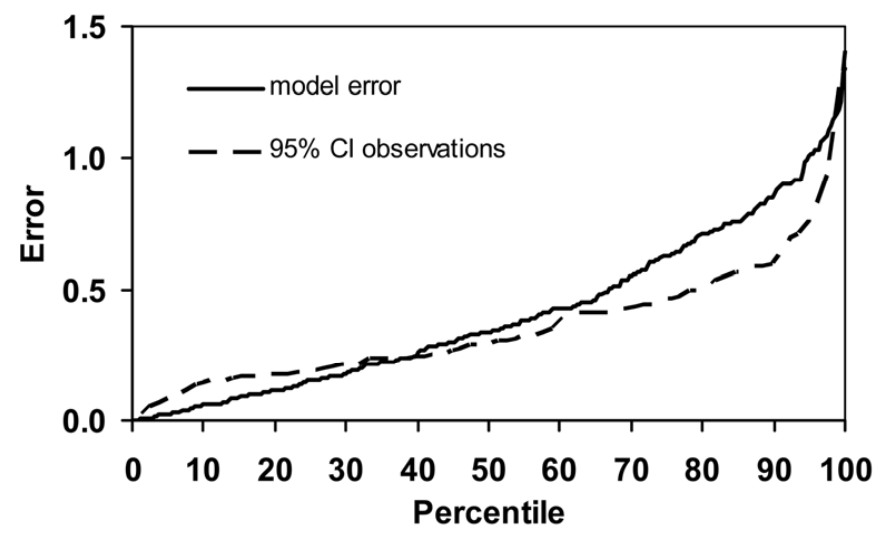

Fig. 6. Comparison of magnitude and distribution of modeling error with magnitude and distribution of observational error for field observations of stem rust. Model error is affected by observational uncertainty, because field observations are used in calculating model error. Cumulative distribution of model errors (absolute values) is shown as a solid line. Cumulative distribution of one-sided values for $95 \%$ confidence intervals computed on each of 78 field observations in disease severity is shown as a dashed line. Each field observation was the average of measurements from three to five replicate plots, with 5 to 10 samples per plot per measurement. 
weather simulated epidemic was $\approx 7$ days earlier than the archived most-favorable year in reaching key disease levels (10, 100, and 1,000 pustules per $30 \mathrm{~cm}$ row). The empirically derived action threshold (Fig. 3A) was not constant during the season, because a higher threshold is permissible toward the end of the season when plant susceptibility is lower and when there is less time remaining before harvest for the epidemic to exceed the damage level. Thus, the threshold has the form of a constant level until early May, then a monotonic increase until mid-June, after which it remains constant. Because the effectiveness of the two common fungicides differs, particularly with respect to contact spread, there are different thresholds for the two fungicide classes (propiconazole and azoxystrobin). The equations for the thresholds as a function of day-of-year ( 1 to 365 ) are azoxystrobin threshold $=500$ for day $<99,10^{(0.026 \times \text { day })+0.156}$ for day 99 to $134,10^{(0.0022 \times \text { day })+3.34}$ for day 135 to 175 , and $10^{(-0.031 \times \text { day })+9.15}$ for day 176 to 185 ; and propiconazole threshold $=75$ for day $<128,10^{(0.04 \times \text { day })-3.23}$ for day 128 to $171,10^{(-0.0155 \times \text { day })+6.23}$ for day 172 to 181 , and 2,500 for day 182 to 185 .

The threshold for azoxystrobin is also used for the fungicide that is an azoxystrobin + propiconazole mixture. The relationship of thresholds to the disease progress curve is shown in Figure 3A. Note that the threshold is implemented as a straight line on a graph that has a logarithmic scale for disease severity. The threshold for each fungicide is not affected by the occurrence of a prior spray of either fungicide.

\section{DISCUSSION}

STEMRUST_G, a simulation model for stem rust of perennial ryegrass grown to maturity as a seed crop, was constructed with algorithms and quantitative relationships derived from experimentation. Model parameters were calibrated by fitting the model to observational data from 10 ryegrass stem rust epidemics. STEMRUST_G includes an autoinfection process unique to this disease (19), and explicitly models a range of effects that fungicides produce on rust population dynamics. This model has fundamental similarities with several other plant disease epidemic simulation models $(4,31)$, principally in their structure based on disease cycle processes such as infection, latent period, and spore production. Our modeling of the pathogen population as age cohorts is similar to the "boxcar" approach in BARSIM (31).

Compared with analytical models for disease progress (e.g., logistic or Gompertz models that express disease as a function of time), simulation models are more complex. This complexity has disadvantages for making succinct, general statements about epidemic behavior. On the other hand, simulation models are well suited to quantifying epidemic behavior, particularly where one intended purpose is to quantify daily levels of disease. There are several influential processes in plant disease epidemics that can change nonuniformly over time, such as host growth and senescence, weather favorability, or sporulation intensity, and this nonuniformity results in epidemic progression that does not necessarily increase monotonically (14). Simulation models can readily accommodate these irregular events. These models can also include fungicide effects in which pre- and postinfection activity occurs and is applied differently to lesions depending on their age. Accommodating these effects on daily disease levels is essential for a model intended to be used as a decision aid. This type of model, once constructed and determined to adequately reflect real outcomes, also allows for comparison of historical or projected patterns of daily weather on epidemic dynamics. We note that the model as presented here is not a forecasting model because the weather data input file does not include forecasted weather data. However, very little modification would be required to run the model with forecast weather data.

As is true of all models, STEMRUST_G is a simplification of the processes that interact to produce an epidemic. For example, although stem rust in ryegrass typically develops as disease foci, this model is not spatially explicit. It does not account for development of disease foci and their effects on dispersal and temporal increase. Instead, temporal disease development is modeled and the model is calibrated to conform with observed disease levels averaged across spatially heterogeneous occurrence. A spatially structured model would be informative with this disease, particularly if practical disease assessment and management were based on prevalence and intensity of disease foci. Under current practice, the average disease severity (as construed by the disease manager) typically is the observation of interest in making disease management decisions. Another major simplification in STEMRUST_G is the use of the single parameter $k$ to summarize several interacting dispersal and biological processes. Quantitatively, $k$ represents the ratio between the amount of sporulation in pustules and the amount of resultant inoculum that arrives at the plant surface. This inoculum is measured as the number of units capable of initiating the next cycle of infection under optimum weather conditions. The effect of lesion density on sporulation dynamics (15) or urediniospore infection efficiency (28) are omitted from the algorithm for sporulation as a function of age, as are a number of other phenomena involved in dispersal. In model construction, the choice of which processes to omit and simplify is affected by the nature of the modeled diseases and the intended use of model. Audsley et al. (3), creating a simulation model for diseased leaf area produced by four different wheat pathogens, simplified disease cycle biology to a generic model with parameter values set differently for each pathogen. That model is used in a decision aid to maximize green leaf area through fungicide use. In the case of STEMRUST_G, stem rust is the only significant foliar disease of ryegrass grown for seed in the northwestern United States; therefore, it is possible to manage crop health using a more detailed model of the disease cycle for this one pathogen.

We found that some epidemiological processes had to be modeled as variable in time, in order to calibrate the model to observed data. We note that some other models share these features. Reduction in susceptibility of plant tissue with time, for which we had prior supporting data (19), is also a feature of some other rust epidemic models $(3,4)$. Our modeling of $k$ as increasing with time is supported by analysis of Yang and TeBeest (33), who proposed that apparent rate of increase gets larger as spatial aggregation decreases when a focal disease becomes more uniform spatially. They noted that the effect would be expected to be smaller for easily dispersed pathogens (such as rust) than for those with a shorter dispersal distance. Another factor that could be involved in a progressively larger apparent rate of increase with time is the location of stem rust disease vertically in the crop canopy. Before and soon after tiller extension occurs, rust lesions are located low in the canopy; however, as lesions appear on upper internodes and inflorescences (whether through aerial or contact spread), the spores are presumably more easily entrained by the wind and moved to more distant, noninfected plant area. Field observations of disease focus development in perennial ryegrass stem rust (W. F. Pfender, unpublished data) reveal a marked increase in the rate of spatial disease spread that coincides with the appearance of sporulating lesions in the upper part of the canopy. We note that our range for $k$, when multiplied by our infection factor of 1,000 (for highly favorable weather conditions), produces expected values of 40 to 200 daughter pustules per pustule. This result is similar to the range (50 to 200) experimentally determined for wheat leaf rust autoinfections, which compose over $85 \%$ of total infections (12).

The best obtainable accuracy and precision of the model are expected to occur in the comparison of modeled outcomes with field observations for the data sets that were used to calibrate the model (Fig. 5). This scatterplot illustrates the differences that 
occur between modeled and observed disease levels for all observation dates subsequent to the observed starting disease value. If there were no discrepancy between model and reality and no observation error, the errors all would be zero. Note that this figure does not represent forecasting ability, because the model was run with extant rather than forecasted weather data. On average, the model produces essentially the same result as the observations; that is, over the range of $6 \log _{10}$ units, the average error (bias) of 0.04 is close to 0 , and it is little affected by the time duration between initial observation and modeled outcome. On the other hand, the variability of the errors around the average is considerable. Of the calculated errors ( $\log _{10}\left[\right.$ modeled] $-\log _{10}$ [observed]), $67 \%$ (one standard deviation) are $\leq 0.51$, or a 3.2 -fold difference $\left(10^{0.51}=3.2\right)$ and $95 \%$ (two standard deviations) are $\leq 1.01$ (10.2-fold difference). There is likely a strong contribution of measurement error to this imprecision in the modeled outcomes. It is difficult to obtain a precise estimate of stem rust severity in a stand of ryegrass, due to spatial heterogeneity of the disease and the prohibitively long time needed to view the leaf area through the entire canopy depth in multiple samples. A calculation of measurement error, based on variance among replicate-plot measurements, shows that the $95 \%$ CIs for a population of 78 of these measurements range from 0.02 to 1.4 (1.05- to 25-fold), with one- and two-standard-deviation levels of 0.41 (2.6-fold) and 0.76 (5.7-fold), respectively. Thus, the observational variance could account for a substantial part (roughly half to three-fourths) of the variability seen as model error (Fig. 6). In a pragmatic sense, this substantial observation error is part of the real-world system in which the model is to be used. The magnitude of this observational error highlights the need to develop disease assessment methods with better precision or with improved efficiency that would allow greater sampling intensity. This source of error sets a limit on the degree of precision that could be obtained even with a perfect model. It is in this context that the model should be assessed for its accuracy and its performance in crop management, which are addressed in the accompanying article (22).

The action threshold was derived empirically to represent a "negative threshold" (16) (i.e., a threshold representing the upper limit of allowable disease at any particular time that will meet the goal of avoiding economically damaging severity during the remainder of the season). This empirical derivation must be done with the use of a weather data input file, and the favorability of that weather for stem rust development affects the value determined for the threshold. If the weather data file comprises extremely unfavorable epidemic weather, the threshold will prove too high in most years; input data for extremely favorable weather will produce an unrealistically conservative (risk-averse) threshold. We chose to use an artificial, composite weather data file created with highly but not extremely favorable weather: each day of the year had the 75 th percentile favorability for that day from a population of 14 years of actual data. This threshold proved to be slightly conservative (risk averse) for the single year whose weather had the highest rust potential among the 14 datasets. One could adjust the threshold, based on historical local weather, to be more or less conservative than the threshold we developed from this input file.

This model was produced with data obtained primarily from one variety of perennial ryegrass, Morningstar. This variety is generally considered to be midway in what is a rather narrow range between highly susceptible and less susceptible varieties currently grown in the region. Therefore, we expect the model will be representative of most stem rust epidemics in this crop. However, the model may not perform as well or may require different parameter values when applied to cultivars that differ greatly in level of susceptibility or growth dynamics from those typically grown for seed in the northwestern United States and many other parts of the world.

\section{ACKNOWLEDGMENTS}

We thank S. Seguin for excellent technical assistance in this research. The use of trade, firm, or corporation names in this publication is for the information and convenience of the reader. Such use does not constitute an official endorsement or approval by the United States Department of Agriculture or the Agricultural Research Service of any product or service to the exclusion of others that may be suitable.

\section{LITERATURE CITED}

1. Amorim, L., Berger, R. D., Bergamin Filho, A., Hau, B., Weber, G. E., Bacchi, L. M. A., Vale, F. X. R., and Silva, M. B. 1995. A simulation model to describe epidemics of rust of Phaseolus beans. II. Validation. Phytopathology 85:722-727.

2. Andrade-Piedra, J. L., Hijmans, R. J., Forbes, G. A., Fry, W. E., and Nelson, R. J. 2005. Simulation of potato late blight in the Andes. I: Modification and parameterization of the LATEBLIGHT model. Phytopathology 95:1191-1199.

3. Audsley, E., Milne, A., and Paveley, N. 2005. A foliar disease model for use in wheat disease management decision support systems. Ann. Appl. Biol. 147:161-172.

4. Berger, R. D., Hau, B., Weber, G. E., Bacchi, L. M. A., Bergamin Filho, A., and Amorim, L. 1995. A simulation model to describe epidemics of rust of Phaseolus beans I. Development of the model and sensitivity analysis. Phytopathology 85:715-721.

5. Chester, K. S. 1943. The decisive influence of late winter weather on leaf rust epiphytotics. Plant Dis Rep. (Suppl.) 143:133-144.

6. Del Ponte, E. M. 2006. Predicting severity of Asian soybean rust epidemics with empirical rainfall models. Phytopathology 96:797-803.

7. Eversmeyer, M., and Burleigh, J. 1970. A method of predicting epidemic development in wheat leaf rust. Phytopathology 68:805-811.

8. Gent, D.H., Mahaffee, W. F., McRoberts, N., and Pfender, W. F. 2013. The use and role of predictive systems in disease management. Annu. Rev. Phytopathol. 51:267-289.

9. Gordon, T. C., and Pfender, W. F. 2012. Effects of the mycoparasite Sphaerellopsis filum on overwintering survival of stem rust in perennial ryegrass. Plant Dis. 96:1471-1481.

10. Hampton, J. G. 1986. Fungicidal effects on stem rust, green leaf area, and seed yield in 'Grasslands Nui' perennial ryegrass. N.Z. J. Exp. Agric. 14:7-12.

11. Kropff, M., Teng, P., and Rabbinge, R. 1995. The challenge of linking pest and crop models. Agric. Syst. 49:413-434.

12. Lannou, C., Soubeyrand, S., Frezal, L., and Chadoeuf, J. 2008. Autoinfection in wheat leaf rust epidemics. New Phytol. 177:1001-1011.

13. Moschini, R. C., and Perez, B. A. 1999. Predicting wheat leaf rust severity using planting data, genetic resistance, and weather variables. Plant Dis. 83:381-384.

14. Nelson, S. C. 1993. Disease progress, defoliation, and spatial pattern in a multiple-pathogen disease complex on white clover. Phytopathology 83:419-429.

15. Newton, M. R., Wright, A. S., Kinkel, L. L., and Leonard, K. J. 1999. Competition alters temporal dynamics of sporulation in the wheat stem rust fungus. J. Phytopathol. 147:527-534.

16. Paveley, N. D. 1997. Determinants of fungicide spray decisions for wheat. Pestic. Sci. 49:379-388.

17. Pfender, W. F. 2001. A temperature-based model for latent period duration in stem rust of perennial ryegrass and tall fescue. Phytopathology 91:111116.

18. Pfender, W. F. 2003. Prediction of stem rust infection favorability, by means of degree-hour wetness duration, for perennial ryegrass seed crops. Phytopathology 93:467-477.

19. Pfender, W. 2004. Role of phenology in host susceptibility and withinplant spread of stem rust during reproductive development of perennial ryegrass. Phytopathology 94:308-316.

20. Pfender, W. F. 2006. Interaction of fungicide physical modes of action and plant phenology in control of stem rust of perennial ryegrass grown for seed. Plant Dis. 90:1225-1232.

21. Pfender, W. 2009. A damage function for stem rust of perennial ryegrass seed crops. Phytopathology 99:498-505.

22. Pfender, W. F., Coop, L. B., Seguin, S. G., Mellbye, M. E., Gingrich, G. A., and Silberstein, T. B. Evaluation of the ryegrass stem rust model STEMRUST_G and its implementation as a decision aid. Phytopathology. 105:35-44.

23. Pfender, W. F., and Eynard, J. 2009. Field assessment of a model for fungicide effects on intraplant spread of stem rust in perennial ryegrass seed crops. Phytopathology 99:696-703.

24. Rapilly, F. 1979. Yellow rust epidemiology. Annu. Rev. Phytopathol. 17:59-73. 
25. Roelfs, A. P. 1985. Wheat and rye stem rust. Pages 3-59 in: The Cereal Rusts, Vol. 2. Diseases, Distribution, Epidemiology and Control. A. P. Roelfs and W. R. Bushnell, eds. Academic Press, New York.

26. Rossi, V. Racca, P., Giosue, S., Pancaldi, D., and Alberti, I. 1997. A simulation model for the development of brown rust epidemics in winter wheat. Eur. J. Plant Pathol. 103:453-465.

27. Rowell, J. B. 1984. Controlled infection by Puccinia graminis f. sp. tritici under artificial conditions. Pages 291-332 in: The Cereal Rusts, Vol I. W. R. Bushnell and A. P. Roelfs, eds. Academic Press, New York.

28. Sache, I. 1997. Effect of density and age of lesions on sporulation capacity and infection efficiency in wheat leaf rust (Puccinia recondite $\mathrm{f}$. sp. tritici). Plant Pathol. 46:581-589.

29. Savary, S., Teng, P. S., Willoquet, L., and Nutter, F. W., Jr. 2006.
Quantification and modeling of crop losses: A review of purposes. Annu. Rev. Phytopathol. 44:89-112.

30. Sundin, D. R. 1999. Triazole seed treatments suppress spore production by Puccinia recondita, Septoria tritici, and Stagonospora nodorum from wheat leaves. Plant Dis. 83:328-332.

31. Teng, P. S., Blackie, M. J., and Close, R. C. 1980. Simulation of the barley leaf rust epidemic: Structure and validation of BARSIM-I. Agric. Syst. 5:85-103.

32. Welty, R. E., and Azevedo, M. D. 1994. Application of propiconazole in management of stem rust in perennial ryegrass grown for seed. Plant Dis. 78:236-240.

33. Yang, X. B., and TeBeest, D. O. 1992. Dynamic pathogen distribution and logistic increase of plant disease. Phytopathology 82:380-383. 